\title{
The Impact of Old Age Pension on Households and Social Relationships in Lesotho
}

\author{
Pius T. Tanga, $(P h D)$ \\ National University of Lesotho \\ Department of Social Anthropology/Sociology \\ P. O. Roma 180 \\ Email: tanga8_2000(1)yahoo.co.uk
}

\begin{abstract}
Austract
The findings of this paper are drazm from an old age pension study conducted in Manmn Constituency, Lesotho and it examines the extent to which old age pension impacts on pensioners' households and socinl relationships. Survey data wons supplemented by datn from in-depth interviezus with key informunts. The consequences of lingh unemployment and the high HIV/AIDS rate have prompted the aged to be caregivers in Lesotho because of their old age pension. The findings show that pension money has strengthened the decision-making process in most households $m$ favour of the aged. An ozerwhelming number of pensioners have total control of their pension, especially the men. Despite the rigidity of these old people with their pension pay package, more than a quarter of the pensioners take care of orphans. In addition, about two-fifth of them were supporting the education and training of some household members through the provision of uniforms, stationery and shoes. The study also revenls that the African culture of respect for the elderly is still much alive in Lesotho. Most of the pensioners reported excellent relationship with and respect from members of their households, more especially their grandchildren. Despite the small amount of pension, it has given a new dimension to the lives of the pensioners and also strengthened and reinforced the spirit of the African brotherhood in Lesotho.
\end{abstract}




\section{Introduction}

The elderly people in Lesotho are playing the role that is supposed to be performed by their children because, rather than being taken care of by these young ones, they now shoulder this responsibility as breadwinners and caregivers. Two factors among others that are responsible for this are HIV/AIDS and unemployment. First, the spread of the HIV/AIDS pandemic at the prevalence rate of 28.9 percent has left an orphan population of more than 90,000 (UNDP, 2015; Minister of Finance, 2005). Tanga and Manyeli (2006) in a survey in 30 villages in the study area found that there were 627 double orphaned children. HIV/AIDS has eroded households' most valuable asset, that is, their labour. This causes affected households to be trapped in what the UNDP (2005) calls a 'financial pincer' as well as a rise in health cost and a fall in household incomes. The demographic shock from HIV/AIDS in most African countries has been described as exceeding that of the First World War (UNDP, 2005). Second, the unemployment rate is estimated at fortyfive percent. Of the fifty-five percent who were employed, seventy percent were working in Lesotho while the other thirty percent were in South Africa (Rapolaki, 2001). The current waves of retrenchment from the South African mines which had served as a main source of household livelihood for most Basotho family had worsened the already high unemployment situation of the country (for example in 1984, 130,000 Basotho were employed in these mines but by 2002 , the number had drastically dropped to 62,125 , a more than 52 percent fall (Global Policy Network, 2004). It should however be noted that while the men dominated employment in the South African mines, the labour force of the clothes and textile factories is principally made up of women. In their study, Tanga and Manyeli (2006) found that 
186 Reveru of Southern Africun Studie's Vol. 12, No. 1 \& 2, 2008

of the total of five hundred and sixty-three households, four hundred heads of households were unemployed while the rest were mostly employed in the informal sector.

This growing unemployment of migrant workers is also compounded by the retrenchment from the clothing and textile factories as well as the closure of some. These factories have much-roomed in the last decade under the influence of the US African Growth and Opportunity Act (AGOA) until by 2006 they provided formal employment to over 60000 Basotho (Government of Lesotho, 2004) Unfortunately, many people have lost their jobs from these factories due to the halt of AGOA that opened the United States, Canadian and European markets to some African countries, including Lesotho. Nevertheless, according to Rapolaki (2001), the factors responsible for unemployment in Lesotho are poor economic performance, high growth rate in the potential available labour force, and continuous retrenchment from South African mines. These factors among others led UNDP (2005) to conclude that survival chances in Sub-Saharan African are not much better than those in 1840s England. The development challenges facing the developing countries are enormous. At stake is the prospect of many people to escape poverty, disease and illiteracy (Allen and Leipziger, 2005).

The above factors have therefore shifted the responsibility of breadwinners and caregivers in Lesotho from the youth who are economically active members of households to the elderly and children. In Malaysia, another developing country in contrast, Lillard and Willis (1997) found that transfers from children to parents were an important source of old age support. It is believed that the introduction of the old age pension in Lesotho in November 2004 as a poverty reduction device has contributed to this 
shift of events in the lives of old people and their household members. As part of a large study on the impact of old age pension on the individual pensioner and household members, the objectives of this paper are to: (1) Examine the role of pension within the context of intra- and interhousehold relationships as a result of old people receiving the newly introduced pension. (2) Scrutinize the decision making process within households. (3) Explore the social relationships between the recipients and other household members as well as members of the larger community.

The introduction of old age pension can be seen as a "social contract" between the government and its citizens in Lesotho, which has exceptionally not been donor-driven. It was introduced from the start as a permanent and not a pilot initiative that could be abandoned after the experimental period.

In South Africa, old age pensions have been found to be an important safety net for the elderly as well as their households because they provide a reliable and stable source of income (May, 2003). Although old age pension is targeted to support the elderly as individuals, in most of the developing countries where it has been introduced, it has become a source of income for household members. The old age pension in Lesotho has enormous potential to reduce poverty among the older people and their households. It is grounded within a rights based approach as well as being linked to wider development. The pension is only likely to be sustainable if it is considered in this holistic manner, as both an instrument of social policy promoting both investment and consumption. According to Barrientos (2005), many studies have shown the positive impact of old age pensions (non-contributory pensions) on poverty reduction and its positive effects on the individual 


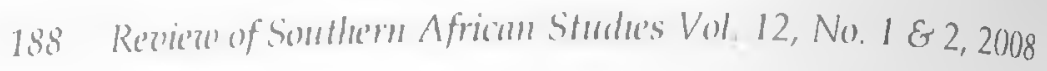

beneficiary, his/her household, human and physical capital investments, intergencrational transfers, local economic activity and the insurance of poorer rural communities from vulnerability of unexpected changes in the environment.

An emerging household type in this era of HIV that has seemingly come to stay is a houschold headed by the elderly. This is apparent, with the large number of youth aged 15-49 being infected with the pandemic. Consequently, the elderly are left to handle the direction of many households in Lesotho. This type of household, that is, elderly living by themselves and elderly living only with dependent children have been identified in many other African countries (Kakwani and Subbarao, 2005). These households show higher poverty gap ratios whose differences are statistically significant from the national averages. Kakwani and Subbarao also suggest that the elderly are not always over-represented among the poor in many countries but rather, the children are abandoned to the care of the elderly. This view is echoed by Food and Agricultural Organisation/World Food Programme (2005) when it states that older people in Lesotho are relativelv secure and as such not the most vulnerable group. This is because the elderly in Lesotho have access to land, pensions, and remittances from the children and relatives both in and out of the country. However, the Lesotho Government policy statement regarding the introduction of old age pension in 2004 clearly stated that this represented government policy on caring for the most vulnerable groups in the society, especially senior citizens who are requiring social protection against old age (Government of Lesotho, 2004). The government aimed to increase the living standards of old people and reduce poverty in keeping with Lesotho's development strategies as contained in the 
National Vision 2020 and the Poverty Reduction Strategy Paper.

\section{Methodology}

The data for this paper are drawn from the findings of a survey of old age pension study that was conducted from March 27 to April 7, 2006 at Maama Constituency not far from the National University of Lesotho. A total of 430 households with a population of 1825 and 215 pensioners were purposefully selected and interviewed. The main instruments of data collection were two semi-structured questionnaires; one for households and the other for pensioners. The instruments were piloted and administered by trained Research Assistants under the overall guidance of supervisors. Open-ended questions were coded and the questionnaires were then captured and analysed with the help of the Statistical Package for the Social Sciences (SPSS). In-depth interviews were conducted from March 12 to March 14, 2007 with key informants in four villages in order to supplement the survey data. The four villages purposefully selected include Nyakosoba, Mafetoane, Mafikeng, and Tloutle.

\section{Findings and Discussion}

Deciston-making process in pensioners' households

It is obvious that in many households where the elderly are regarded as a dependent population, household decisionmaking sometimes elude them. However, given the strength of money in influencing the decision-making process in households, we attempted to find out how decisions are arrived at in the pensioners' households, especially the use of their pension. It must be remarked that the findings may be skewed because 68 percent of the pensioners were head 
190 Rerierue of Southern Afrocm Studues Vol. 12, No. 1 \& 2, 2008

of households, 65 percent widowed and 7() percent living with other family or household members. Overall, the findings showed that 95 percent of the pensioners were in total control of their pension with the exception of five percent who had given the mandate to their family members to collect and control the use of their pension.

To further probe into the decision making process of the pensioners, in-depth interviews were conducted in four of the villages where the main survey took place. The findings showed that more than 90 percent as observed above, especially the men were collecting their pensions by themselves and took decisions on how their pension is used; they decide what to buy for their households and whether to save part or invest it. However, in the case of ill-health, they maintained that they normally delegate a relative or one of their children/grandchildren to collect the money on their behalf. In an interview with one of the respondents aged 85 (March 13, 2007) in Mafikeng he revealed this:

I have been collecting the pension by myself but due to old age. I sometimes asked my sister-in-law to collect it for me from the Roma Post Office. When she hands the money to me, I decide what to buy for the household and how much to save if there is any balance left. If I collect the money miyself, I immediately buy mealie Mealie, paraffin and soap at the nearest shop at Ha Mafefoane.

In another interview with a 72 years old women in Mafefoane (March 13, 2007), she revealed that her husbands normally collects her pension and buys households needs that she has instructed him to. According to her "I make the final decisions on how the money should be spent, because the wife is the one who knows all family needs". Similarly, the daughter of an 81 years old respondent in Mafikeng 
takes full responsibility of collecting and utilising the pension for the old woman but with instructions from her. An exceptional case was found at Nyakasoba during an interview (March 12, 2007) whereby the 97 years old man collects his pension himself but according to him:

My wife is the one who decides on how the money should be spent because I might misuse it. As a rooman, she knows every- thing that is needed in the house/family. However, it is me who has given her the primlege and not her right to decide because our culture does not permit a woman to take family decisions except when it comes to food that has to be put on the table.

Interestingly, the wife is a disabled person, though she can take care of herself as the husband declared. It should be noted that since others stay alone, they are responsible for deciding on what to do with their pension. One of the elderly aged 70 years from Nyakosoba stated in an interview (March 12, 2007) that:

I collect my pension from the Nynkosoba Post Office and then buy small grocery for myself such as soap, mealie mealie, sugar, paraffin, etc at the nearest shop that very day and I keep the rest of the money to buy groceries at some other times. I also pay M40 for burial society. Since I stry alone, I make my decisions on how to use the money. I plan to invest my money because my grandchildren and some other people might steal it. If I were living with some relative I will still do the same because it is my money and not theirs. When they have theirs, they will never ask your opinion about what you even need not to talk of household needs. 
The above analysis shows that as typical Africans, pensioners, the men especially do the collection and decide on how the pension should be used. It is at their discretion to help in the provision of household needs as well as extend a hand of fellowship to other needy household members such as orphaned children. Even when the asked others to collect the pension for them, strict instructions are normally issued to the collector on what should be bought and in what quantities. Despite the rigidity of these old people with their pension, the section below describes their largess to orphaned children. Some of them believe that if they can not help the young ones, at a more advanced age, they might be neglected, what many do not wish for.

\section{Pension and support to orphaned children}

The support to orphaned and vulnerable children has become a national priority in Lesotho given the high rate of HIV/AIDS which has left thousands of orphaned children. In this light, the government has established a national coordinating committee to oversee their rights and welfare. May be in line with this priority which may be coincidental or pensioners' liberality, some orphaned children are equally benefiting from the pension of the elderly. Out of the 215 pensioners interviewed, 62 of them constituting more than 28 percent take care of orphans (grand and great grand children) from their meagre pension. Since there was more than one orphan in some households, the findings showed that there were a total of 96 orphans made up of more than 52 percent males and about 48 percent females. However, only 65 orphans were depending on the elderly support for their needs. The majority of all the orphans fell between the ages of one year to ten years and another sizeable number between 11 and 19 years. Only a few were from 19 to 22 
years and therefore relatively more able to be independent. The findings further revealed that more than 65 percent of the orphans had lost both parents to HIV/AIDS and other diseases; about 34 percent still had one parent. More than two-thirds (65) of the orphans have been in the care of these pensioners and they have been in their care for between one to six years. This shows that these elderly people probably had started taking care of these orphans before the introduction of the old age pension in Lesotho in November 2004. A small fraction of the orphans have been cared for between seven to ten years while the others have been between 11 and 22 years.

Assistance rendered by the elderly to orphans is not only provided by old age pensioners in Lesotho, it is also common in Zambia, Uganda and rural Tanzania, where Deininger, Garcia and Subbarao (2001) found that more than one-third of orphans are catered for by grandparents as primary caregivers. They noted that although the surviving parents are caregivers, the burden is shifted to the grandparents when children become double orphans. As a result, households turn to the elderly for financial as well as emotional and physical supports. The introduction of the old age pension in Lesotho surely has been beneficial to orphans and children of the elderly in Lesotho.

The respondents were asked how much the orphans were getting from their pension on a monthly basis. It was stated that 63 percent of the orphans were not directly benefiting from their pension, that is, their needs could be accommodated by the household income without necessarily using the pension grant. About 15 percent of the orphans were receiving about fifty Maloti (M50) on a monthly basis while the rest could get from one Maloti to forty Maloti, except two who were each receiving 60 and 100 
Maloti per month (Maloti is the local currency which is at parity with the South African Rand). On the average, the respondents were spending 30 Maloti a month and this constitutes 20 percent of the money they receive as pension from the government. These amounts must be seen in terms of the size of the pension, which is set around the national poverty line for one person. Given the willingness of the recipients who are already close to the poverty line to share in the extra burden of accepting orphans into their households is a testimony to the continuing strengths of the welfare safety-nets that families are able to provide. There is similar evidence from the survey of pension income being used to help other family members and even neighbours in need.

Because the pension is unlikely to lift the pensioner and/or household members above the poverty line, it is not surprising that only four percent of the respondent could save any money after receiving their pension and that only a few could invest in income generating activities. It is significant that the small amounts that were spent from the pension had created 45 new jobs, mainly for domestic help. The Roma Valley sample constitutes about one-third of one percent of the 75000 people getting the old age pension. On the heroic assumption that the sample is representative of all Basotho pensioners, the response would indicate that the impact of the pension could be creating around 12000 new jobs.

In South Africa, Schatz and Ogunmefun (2005) also found that most of the female pensioners invested their money in rotating credit scheme and buy building materials for their houses and other household items when it is their turn. Even in South Africa where the old age pension is five times larger than the pension in Lesotho, and households 
have access to other cash transfers such as child allowances and disability benefits, most recipients claim that they have no money left after basic household expenditures, an indication that in developing countries like those in Southern Africa, a non-contributory pension will never meet more than a basic social protection instrument. Indeed, the central justification for old age pension in a country like Lesotho is not that it solves the poverty position of the pensioner and their household. At the best it is a symbol of the political will of the government to freely transfer a little of its scare resources to old people as one element of their human rights. If a pension recipient as is apparent in Lesotho, on their own volition decides that some of that pension must be transferred to their household, then this is a another step in the enhancement of social protection

In Lesotho, the motive for an elderly person to offer this help to the household is not very clear. However, in-depth interviews conducted revealed that most of the pensioners see the assistance or support they provide to orphaned children who are either their grandchildren or children of relatives as their responsibility since they claim that there is no one else to help them. One of the pensioners, 78 years old man from Tloutle (March 14, 2007) maintained that:

It is my obligation to help the orphans with whom I have been living for many years before I began receiving pension two years ago. Before I started getting this pension, other fnmily members zuere helping me and some are still doing this and why should I now refused to help others because I am earning pension which is even small. If the pension seizes to be paid and I wors not helping others, how rwould I live without help from the family? I don't expect anything in return for helping them. Right now, I am paying M40 for the 
196 Reriere of Sonthern African Studies Vol. 12, No. 1 \& 2, 2008

hurial society so that when I die, they zould not have much to do. If they do, it zuill be their wish.

However, some contrary views were found elsewhere during the interview sessions. A 72 years old woman from Mafefoane interviewed (March 13, 2007) indicated that:

There are no orphans in the fomily. Had they been, I would help them for charity and out of pity. Hownezer, the pension is too little for me to help the orphans, but if it were to increase, I would help them for the sake of helping without aniy strings attached.

Another woman, aged 102 years from Mafikeng village interviewed (March 14, 2007) had a different view from the above two respondents and according to her, she maintained that:

I would like to continue to help orphans and treat them equally because they would do same to me, that is, they would take care of me at a later stage of my life. Even now, they are already helping me with fetching rwood and water as well as washing my clothes.

In respect to whether they would help boys more than girls, none of those interviewed answered in the affirmative. They both stated that whether boys or girls, they are all their children or grandchildren/great-grandchildren and did not see why they should discriminate against any one because of their sex. However, some were of the opinion that they would treat them different if there were younger and tender ones among them. Because of this then, they would give preferential treatment to the younger ones based on age and not on sex. This shows the positive changing attitude in this 
direction in Africa. In the past, boys were preferred, especially on parents' preference for their education and other entitlements since they held that girls get married and are seen as the 'property' of others while the boys are seen as those to continue with the family name and lineage.

On the African continent, it is strongly believed that parents help their children both for unselfish reasons and because they anticipate they may be helped in return. Kochar (2002) shows that literature on intra-household allocations is not based on altruistic income sharing but influenced by the bargaining weight of utility of every household member. As a network of social relations, family members of different generations constitute an internal credit market whereby the demand for credit is generated by one generation and the credit is supplied by another generation. Membership in these social networks, which include the family, provides a substitute for absent or imperfect credit and insurance markets. However, Kochar (2002) reveals that family networks maintain their economic value at a significant cost, for example a family may be transferring income to elderly members by spending less on providing schooling for younger generations. The provision of old age support by children will vary depending on the perceptions of the values of such trade-offs. Apart from the support to orphaned children, the study revealed that pensioners also use their pension in supporting the education of other household members as discussed below.

\subsection{Pension and support to the education of other household members}

Another dimension of the African traditional support system is in education and training, just like in other developing countries. In Brazil for example, Rangel (2004) in a study on 
alimony rights and intra-household resource allocation found that after the intra-household empowerment of women through the December 1994 extension of alimony rights to a large fraction of couples in consensual unions, there was an increase in the consumption of leisure by women and a reallocation of resources towards the schooling of older girls. In Lesotho according to the findings during in-depth interviews, the education of all children is paramount irrespective of sex or age. However, more girls attend schools than boys not because the boys are seen as inferior but because it is believed that they have to look after cattle or work in the South African mines in order to better support the family through remittances and/or other ways. Each family in Lesotho strives to have at least one boy or person in the South African mines because it is a pride to have somebody 'abroad'.

The findings of this study revealed that prior to the introduction of old age pension in Lesotho, the educational and training needs of some of the household members were catered for by more than 57 percent of the mothers of the children, about a quarter by the elderly people themselves and the rest which made up about five percent were under the responsibility of their relatives. All of these were in the name of African traditional support system. After the introduction of the old age pension in November 2004, about 40 percent of the respondents indicated that they were supporting the education and training of 132 household members. This shows an increase of about 15 percent from the previous percentage of the elderly that were supporting the education and training of family children. The 132 household members whose education and training was being supported constitute more than 64 percent of those household members that were attending school and/or 
college while only about 35 percent were not being supported, for one reason or the other. It should be noted that there is free primary education in Lesotho and some of the children might not have been helped since they are benefiting from this free education. The bulk of those supported were in primary school, that is, between standard one and seven (about 74 percent). A small number were between Form $A$ and Form $E$ while the rest were in vocational training schools and in un-stated type of education and training institutions.

About 40 percent of those whose household members were supported were doing well in their studies or training while more than 43 percent were just average students. However, slightly more than 17 percent were performing poorly in their various schools. The good performance of students is a motivating factor to push parents and elderly people like these old age pensioners to continue to disburse their meagre pension to their education and training. Of the 85 respondents who assisted household members' education and training, the majority (more than 52 percent) provided uniforms for them, about 26 percent assisted with stationery. School trips made up about 13 percent of those respondents who sponsor them and less than five percent provided shoes for household members attending schools and colleges. The rest of the respondents indicated that they help household members who are in school with school fees, transport, toiletries and groceries. School fees would have been the most important thing that should constitute help to household members attending school and other training institutions but for the fact that primary education is free, with the government even providing books that are lent at very subsidize costs in some secondary schools. 
200 Rernerw of Southerm African Studties Vol. 12, No. 1 \& 2, 2008

Furthermore, double orphans (those who have lost both parents) are sponsored by Global Fund through the Ministry of Education. Given that the pension is only M200 per month, the majority of respondents $(80$ percent) stated that their pension was grossly inadeyuate to meet the educational and training needs of members of their households that they help. Only 20 percent held the view that their pension was adequate in meeting these needs. Most probably, these were wealthy pensioners whose income source is not only pension. On the average, respondents spend up to 60 Maloti monthly to support school children living in their households and this constitutes about 20 percent of the pension they receive. Most of the pensioners expressed the wish to see the pension increase to $\mathrm{M} 400$ and the age reduce to 51 years. If this was to be heeded to by the government, the cost of the old age pension to the nation would be eight times and would also constitute 12 percent of GDP which is not even spent in most developed countries. This is because according to the Government of Lesotho (2004), the scheme is currently catering for about 75000 old people and people above 50 years are about 600000 . It should be understood that the purpose of the old age pension was to take old people out of poverty and give them a safety-net and not to carry the burden of eliminating all the social injustices in Lesotho.

Elsewhere in Africa, for instance, among the older women in South Africa pension is considered as a subsidy for their households, especially their grandchildren and not just for their own subsistence. "They are using their pensions as a means for sustaining their intergenerational households, as substitute for unemployed children's income, and as a resource for economic shocks...some women .... are in fact supporting unemployed children, as well as the unemployed 
children's offspring" (Schatz and Ogunmefun, 2005:9). Schatz and Ogunmefun found that although most elderly were helping members of the same household, some also extended the largess to other household members elsewhere, especially in times of crises such as death. They also assist their unemployed children in cities and towns until they find employment. This inter-household support is another aspect of income transfer to members of break-way family. However, Witoelar (2005) argues that the reasons for family break up include getting married and search of jobs in cities and consequently, familial links (extended family) still have economic ties. This doesn't seem to happen the same extent in Lesotho; perhaps because the value of the cash transfer is less than in South Africa and the means of income support are available there. This allows the 'luxury' of helping your neighbour and distant relations as well as the immediate family needs. These ties may be in the form of income transfers between households, that is, inter-household, exchange of gifts and informal loans and these may be motivated by altruistic reasons while others could be for self-interest. This is where for instance, they are provided in anticipation that they will 'buy' the support of children when the donor reaches old age. Households may be involved in inter-household allocation with other households based in other villages or regions and this could be to protect such households from "village-specific economic shocks" (Witoelar, 2005: 2). This may be some form of "insurance group". In Cote d'Ivoire, Grimard (1997) found that individual households provide partial insurance to members of the same ethnic groups who are living across different geographic regions. However, Townsend (1994) note that closer ties between members of extended family rather than ethnicity or geographical proximity could be an 
important factor on which households' informal arrangement is based. The findings of this study, through indepth interviews, showed that most family members are happy about their old ones getting old age pension because it has relieved them of some financial obligations to the pensioners. Although many are excited, they still continue to provide the much needed help that the elderly need in varying degrees. One respondent from Mafefoane, 72 years woman (interviewed March 14, 2007) revealed that:

My fnmly members, even the whole community are excited that some of us are receining pension. However, they are showing little interest in helping me now that I get pension from the government. I still apprecinte the little help they are offering to me because if not of them. I may not be able to do some of things they are doing for me, especially when I must have adranced in age agnin.

Witoelar (2005) emphasises that the lack of social security system and absence of financial and insurance markets is the cause of households' reliance on inter-household informal arrangements so as to smoothen their consumption. In India for instance, 93 percent of households in rural areas receive transfers and while in Malaysia, transfers constitute 46 percent. These extended families are not only expected to assist only in time of crisis but sometimes in human investment of family members. However, there was no evidence to show complete risk-sharing within extended families in Indonesia. Similarly, Hayashi, Altonji and Kotlikoff (1996) reject both inter- and intra-household full risk-sharing. In Lesotho, pensioners also provide support to non-household members for various reasons, such as anticipated help in the future. Also, there is no evidence of any risk sharing in Lesotho. 
Pension and support to non-household members

Many people in Africa do undertake solidarity gestures among themselves, especially to the have-nots or the needy. In Lesotho, the findings of this study revealed that 3 percent of the pensioners indicated that they help people who are not in their households, that is, inter-household support but who are related to them in one way or the other. This was not a way of sharing risk but a gesture of helping for either selfish reasons or self-interest. The ages of non-household members who were being helped by the respondents range from 13 to 17 years. However, others could not determine the ages of those they help. In this category of nonhousehold members, school fees top the type of activity they assisted them with, and this was followed by uniforms and school building. Still, slightly more than 33 percent could not specify the nature of education and training help to the nonhousehold members. Forty percent of these pensioners spend ten Maloti while 20 percent spend about 20 Maloti monthly. While a few could spend up to 120 Maloti, the rest were capable of spending up to 200 Maloti. Pensioners were asked what would happen with the non-household members they help, in case they are no longer provided pension. More than 66 percent made it known that the fathers of the non-household members they help would have to continue from where they stopped. About 33 percent stated that the non-household members would have to discontinue their education and training programmes. In developing countries, Cox and Jimenez (1990) provided evidence to show that inter-household transfers are an important source of income and serve as social insurance.

Apart from education and training of household and non-household members that recipients of old age pension provided assistance to, one respondent revealed that he or 
she assisted one adult in the household to do building construction. According to this respondent, this is to enable this adult to be able to generate more income for himself as well as for the household. The findings also showed that the respondent equally provided daily transportation and money for groceries to the adult building construction trainee. It is interesting to note that Lesotho has a poor system of technical education and as such the government provides grants to those wishing to do technical education in South Africa.

\section{Pensioners' perception of the importance of education}

To assess the importance of education and training in this $21^{\text {st }}$ century and as one of the Millennium Development Goals, as perceived by elderly, the respondents were asked to rate whether investing in education and training of their children and other household and non-household members is more important than accommodation, food, clothes and health. Compared to accommodation, about 21 percent said it was more important, 28 percent were of the opinion that it is equally important while 27 percent stated that investing in education and training is less important than accommodation because they need it as a basic necessity of life. However, some were indifferent to whether it was more important or not. A similar situation was observed with food, clothes and health compared to education and training since people need food for survival as well as clothes, especially warm clothes during the winter as Lesotho is very cold. It should be remarked that Lesotho is rated highly as concerns universal primary education, with the participation of girls even more than boys.

Respondents were asked whether the pension has made things better in terms of meeting educational and training 
needs of their household and non-household members. About 38 percent opined that pension has not made things better in anyway, about 16 percent said it has changed things just a little better. Less than ten percent agreed that pension had made things much better in meeting educational and training needs of their family members. Those who stated that it has made things a lot better may be those who have other sources of income apart from old age pension. This is because many respondents complained that the monthly pension they get from government could not take care of their household groceries, and also other basic needs such as education, health and housing. Overall, children whose parents and/or relatives receive this pension are significantly more likely to be enrolled in school than other poor children of the same age range. Thus, old age pension appears to help overcome the impact of poverty on school enrolment.

The role of the pension can not be underestimated in terms of contributing and strengthening traditional African support system as evidenced from the above analysis. However, because the pension is small, the people would have wished to do more for their loved ones and other family members. Nonetheless, this is better than nothing. Again, a survey of all the more than 70,000 beneficiaries that keeps on increasing every month may reveal fascinating figures and the number of other people being assisted by the beneficiaries. Lesotho government efforts to transfer almost two percent of the income of the nation into the hands of old people must be lauded given that this country is one of the poorest countries in the world and has introduced what much wealthier developing countries have not been able to do despite many of them subscribing to the 
206 Reviezen of Sonthern African Studies Vol. 12, No. 1 \& 2, 2008

recommendations in the United Nations Madrid Plan of Action for Ageing.

Socinl relationship with household and other community members Lesotho like most other African countries has a culture that emphasises respect of the elderly and their role in the family and social hierarchy. According to Nyanguru (2006), this respect forms an important part of community life. The traditional African norms, cultural and other values that existed in the extended family system provided an appropriate and respectful place for the elderly. However, poverty can erode this respect because it is not just the lack of income alone but it also involves the lack of the ability to wield power both in the family and in the community. According to Shandardass (2002), poverty entails a situation whereby one is powerless and voiceless both in his or her family as well as in the conmunity in which he or she lives.

While factors such as urbanisation, industrialisation and social mobility have promoted the break up of extended families, technological changes tend to devalue and undermine the wisdom or life experiences of the elderly. This leads to the loss of status and power. In India for example, despite the fact that children live in the same districts with their old parents, these children still prefer that their old parents should be in the old people's homes rather than stay with them ((Venkatachalam, 2005). Similarly, Amaike (2005) reveals that the elderly destitute in Lagos blame their powerlessness and voiceless-ness on the adoption of aspects of Western culture that have encouraged the nuclear family system. As a result, their children have abandoned them either on the streets or in old peoples homes. In addition, in most African countries such as Malawi, there is conflict between the traditional and modern 
cultures especially in the urban areas that are characterised by insecurity, alienation, competition and individualistic lifestyles. This affects the way household members relate to each other and how they share the available resources (Chipeta, 2005). Chipeta maintains that, on the other hand, the rural areas are characterised by communal life and sharing. In her findings, she notes that although there is solidarity in most families in Malawi, conflict is very evident between the children especially the females and their parents, particularly grandparents. The areas of conflict include issues of cleanliness, clothing, boy friends, household chores as well as studying. Like Amaike on Nigeria, Chipeta ascribes this situation principally to the influence of the Western culture.

The findings of the pension impact study in Lesotho showed that about 42 percent of the respondents had excellent relationship with members of their households before they began receiving their pension. A further 50 percent said pre-pension relationships were satisfactory. Less than ten percent of the elderly had poor and unsatisfactory relationship with members of their households. Although, for most households the pension represented a significant new flow of cash income each month, 73 percent of the pensioners said this had made no change in relationships within the household. Thirteen percent said relationships had much improved and nine percent said relationships were better. Only five percent said household relationships had worsened after getting the pension.

As one would have expected, the fact that many elderly are actively and directly concerned with the support of the youngest members of the household, the pensioners reported getting a lot of extra respect from their 
grandchildren. This is because since getting the pension, they have been able to extend more support to their grandchildren. Only 17 percent has seen no change and only one pensioner in 20 said their relationships with grandchildren had got worse. A similar trend was observed with the respondents' own children who the elderly were now able to assist more. In 58 percent of the pensioner responses, the availability of the pension money was seen as substantially increasing the respect shown to pensioners by other adults in the family. In the remaining cases, no change had been observed. The former view was corroborated during the in-depth interviews that were conducted in four of the villages from March 12 and 14, 2007. It appears from the survey that the elderly have always played this role in Lesotho. The availability of the pension had not made much difference to this, with more than 90 percent of the pensioners confirming this. With respect to the relationship with neighbours, an 87 years old respondent from Mafikeng however revealed that:

I am not in good terms with neighbours all along and not because I am getting pension; as for family members, I am not sure because since I left Nasaretn to Roma some years ago, I have been staying far aziay from them.

Regarding advice, 50 percent of their grandchildren do come to them always for advice, while 30 percent sometimes do come for advice. Only 20 percent either rarely or never seek advice. The same situation was observed in the number of times the children of pensioners as well as other adult family members come to them for advice. Less than 20 percent of adult children and other adults and less than 15 percent of non-family children in the community come for advice quite often. 
Thirty percent of pensioners said that other children and adults in the community sometimes come for advice from them. More than 90 percent of the elderly maintained that there had been no change in the amount of respect they earned from other people. An insignificant number said they were less respected after the pension. This could be because some pensioners might not have been willing to help those in need around them. One of the respondents ( 84 years old woman) confirmed this by revealing that "I have been respected by family members and neighbours all along and not because of pension."

Apart from social relationships with household and community members, we sought to know the perception of pensioners with regards to changes in their lives.

Perception of changes in the lives of pensioners

Although pension has produced no significant change in the extensive help given by the family, especially children overall, about 39 percent of respondents were a lot more satisfied with the way their lives have changed now that they are receiving old age pension. More than 55 percent were a bit more satisfied. These findings showed the important part that old age pension is playing in the lives of the beneficiaries as well as those of their households. An aspect of this may lie in the fact that more than 90 percent of the recipients could state that they themselves were able to control the way their pensions should be used. A few had it controlled by their wives, children and daughter-in-laws. Although pensioners considered they had control over their pension, it is noteworthy that his discretion is exercised so that the majority of the income is transferred to the other members of the household. The survey findings showed that the pensioners themselves have not had up to 40 percent of 
their pension for their personal use. No pensioner could get more than $\mathrm{M} 100$ to spend on himself or herself each month because of the support they provide to other household members with their meagre pension. Such cash transfers such as pension must be regarded as transfers to households and not to individual recipients.

However, seven percent of the respondents indicated that they were being abused. Verbal and emotional abuses were the main types of abuse/ill treatment they received and this made up less than four percent each. Physical abuse/ill treatment constituted less than 1 percent. The findings further revealed that neighbours were those who most often abuse or ill treat them followed by young people in the family and other children in the community. Less than 2 percent of these abuses/ill treatments were attributed to the pension they receive from government. This occurs when their pension money is being stolen from them. One of the pensioners, 87 years who was interviewed from Nyakosoba (March 12, 2007) reported that prior to the pension scheme he had not experience any case of abuse. He said since he began getting the pension, he has been verbally abused by family children and at times, when his money is stolen, he normally suspects them. However, he guessed that the reason may be because he does not give them money which they always demand. It is a taboo in most African countries for a child or other adult person in the community to physically abuse or ill treat an elderly person. However, with an increase in the use of drugs and alcoholism, this African virtue of holding the elderly in high esteem is gradually being eroded in many communities. Also, with modern communication techniques, lifestyle changes are taking place much faster and as such, the values of the young people may be more and more in conflict with the 
views of the old people. The potential for violence from the frustration of not being able to get the elderly person to see that the young person 'need' something may be greater.

\section{Conclusion}

Lesotho is one of the few nations in the world that have a Low Human Development rate but it has also been able to provide its elderly with a significant cash transfer through a non-contributory old age pension, paid to almost everyone purely on the criteria of citizenship and age. Before the pension scheme, most of the pension recipients in Lesotho were already amongst the poorest of a population where poverty is endemic. Because most pension recipients choose to distribute their pension across all the other members of their household, the difference in their income that they can retain is small and unlikely to lift many out of poverty. Before the introduction of the pension, many were unable to neither live a satisfactory life nor assist other household members. They depended entirely on the mercy of their families for support. However, the introduction of old age pension despite its small amount has given a new dimension to the lives of its recipients. They have, in small ways inproved wellbeing not just for themselves but sometimes also for other household members. This has strengthened the relationships between the pensioner and other household members. Therefore, the impact of old age pension on the well-being of the elderly and their households is, overall, positive and significant. How significant it has been is difficult to measure. When most people start with very little, anything additional is significant. At the same time, the addition of the pension income may appear to be making an insignificant impact in closing the poverty gap that confronts most Basotho households. 
The positive effects of the pension can be seen in terms of the increased amount of respect the pensioners themselves are now receiving, the better standards of nutrition and increased support to the education and training among others. The changes are also in line with the aspirations of the Millennium Development Goals and Lesotho Vision 2020 document. In rural societies in Africa, as in most Low Human Development countries, the only safety-nets that are available are built from the informal structure of mutual respects and obligations existing between people. The injection of the ability to pay cash to represent some of these obligations can only strengthen these structures, while at the same times improving the well-being of old people.

\section{Acknowledgements}

The author is grateful to the HelpAge International and Research and Conference Committee of NUL for the financial support for the research which has resulted into this article. However the views expressed in this article are those of the author and do not reflect those of HelpAge International and Research and Conference Committee. 


\section{References}

Allen, M. and Leipziger, D. M. (2005) 2005 Revieu of the Poverty Reduction Strategy Approach:Balancing Accountabilities and Scaling Up Results. New York: IMF/World Bank.

Amaike, G. O. (2005) "Poverty and the Quality of life of Older People in Metropolitan Lagos: A Study of Destitute Elderly". Paper presented at the International Conference organised by Institute of African Studies, National University of Lesotho from November 21-26.

Barrientos, A. (2005) "Non-Contributory Pensions and Poverty Reduction in Brazil and South Africa." Retrieved from www.idpm.man.ac.uk/ncpps, January 22, 2006.

Chipera, L. (2005) "Tension between Tradition and Modernity, Gender and Space." A paper presented at the Gruphel International Conference on "Speaking across Boundaries: Gender Generations and Social Justice in an Urbanised World" organised by the Institute of Southern African Studies, 21 - 25 November, 2005.

Cox, D. and Jimenez, E. (1990) "Achieving Social Objectives through Private Transfers". World Bank Research Observer, 5 (2), pp. 205-18.

Dieninger, K.; Garcia, M., and Subbarao, K. (2001) "AIDS Induced Shock as a Systemic Shock: Magnitude, Impact and Programmatic Interventions in Africa". Washington, D. C.: World Bank.

Food and Agricultural Organisation/World Food

Programme (2005) Special Report: FAOMFP Crop and Food Supply Assessment Mission to Lesotho. Rome: FAO/WFP.

Global Policy Network (2004) "Highlights of Current Labour Market Conditions in Lesotho". Retrieved from www.globalpolic nnetwork.org, November 10, 2005. 
Government of Lesotho (2004) Poterty Reduction Strategy for Lesotho, Maseru: Ministry of Central Planning.

Grimard, F. (1997) "Household Consumption Smoothing through Ethnic Ties: Evidence from Cote d'Ivoire". Journal of Development Economics, 53, pp. 391-422.

Hayashi, F.; Altonji, J. and Kotlikoff L. (1996) "Risk-Sharing between and within Families". Econometrica, 62 (2), pp. 261-94.

Kakwani, N. and Subbarao, K. (2005) Ageing and Poverty in African and the Role of Social Pension. New York: World Bank.

Kochar, A. (2002) Inter-generational Income Sharing and Schooling Investments. Stanford: Stanford University.

Lillard, L. and Willis, R. J. (1997) "Motives for Intergenerational Transfers: Evidence from Malaysia". Demography, 34, pp. 115-34.

May, J. (2003) Chronic Poverty and Older People in South Africa. Chronic Poverty Research Centre (CPRC) Working Paper 25, CPRC and HelpAge International.

Minister of Finance (2005) "Budget Speech for the 2005/2006 Fiscal Year". February 16.

Nyanguru, A. C. (2006) "A Review of the Old Age Pension Scheme in Lesotho." (unpublished manuscript).

Rangel, M. A. (2004) Alimony Rights and Intra-Household Allocation of Resources: Evidence from Brazil, Brazil: Ministry of Science and Technology.

Rapolaki, M. E. (2001) “Review of Lesotho's Development Performance since Independence". Paper presented at the National Dialogue for the Development of a National Vision for Lesotho (Vision 2020) January 17-19, 2001. 
Schatz, E. and Ogunmefun, C. (2005) Caring and Contributing: The Role of Older Women in Multigenerational Households in the HIV/AIDS Era. Boulder: University of Colorado.

Shankardass, M.K. (2002) "Voices of Older Poor in India". Situation and Voices the Older Poor and excluded in South Africa \& India. Population and Development Strategies, No. 2 UNFPA \& CB GS.

Tanga, P. T. and Ts'epang, F.M. (2006) "Baseline Survey of Orphaned and Vulnerable Children in Roma Valley." (Unpublished manuscript).

Townsend, R. (1994) "Risk and Insurance in Village India". Econometrica, 62, pp. 539-92.

UNDP (2005) Human Development Report: International Cooperation at Crossroads: Aids, Trade and Security in an Unequal World. New York: Author.

Venkatachalam, C. (2005) "Living Arrangements for the Elderly in Old Age Homes in a South Indian City". A paper presented at the Gruphel International Conference on "Speaking across Boundaries: Gender Generations and Social Justice in an Urbanised World" organised by the Institute of Southern African Studies, 21 - 26 November, 2005.

Witoelar, F. (2005) "Inter-Household Allocations within Extended Family: Evidence from the Indonesian Family Life Survey".

Retrieved from www.econ.vale.edu/egcentre/research.htm, March 24, 2006. 


\section{(c) (1) (9)}

This work is licensed under a

Creative Commons

Attribution - NonCommercial - NoDerivs 3.0 License.

To view a copy of the license please see:

http://creativecommons.org/licenses/bv-nc-nd/3.0/

This is a download from the BLDS Digital Library on OpenDocs http://opendocs.ids.ac.uk/opendocs/ 